\title{
Deep bite: A treatment planning decision support scheme
}

\author{
Mostafa M El-Dawlatly, Mona M Salah Fayed, Ahmed Mohamed Heider and Yehya A Mostafa* \\ Department of Orthodontics and Dentofacial Orthopedics Faculty of Oral and Dental Medicine Cairo University, Cairo, Egypt
}

\begin{abstract}
Deep bite malocclusion is one of the most common malocclusions that have a multifactorial nature; with a multitude of underlying components, while various dental and facial parameters could affect the decision making process. This study aimed to customize a step-wise systematized diagnostic tool that could aid the clinician in the decision making process for deep bite cases. We used the data provided by 124 deep overbite cases to elucidate the most eminent underlying components of deep bite malocclusion, moreover a literature review was done that clarified the various contributing factors to the decision making of deep bite. Using this data a systematic diagnostic sheet is presented to aid the orthodontist in designing the treatment objectives of deep bite malocclusion.
\end{abstract}

\section{Introduction}

Orthodontists are required to make decisions regarding treatment on an everyday basis. However, under higher time pressures (as is typical in a busy orthodontic clinic), or with increased ambiguity, experts use intuitive decision making rather than structured methods to arrive at a satisfactory course of action without due regard to all factors and alternatives.

Deep overbite is one of the most common malocclusions in orthodontic practice [1]. Severe deep bite (overbite $\geq 5 \mathrm{~mm}$ ) is found in nearly $20 \%$ of children and $13 \%$ of adults, representing about $95.2 \%$ of the vertical occlusal problems [2].

Deep bite malocclusion (DBM) overlies a multitude of hidden skeletal and/or dental discrepancies. Hence, the mechano-therapy should be directed to resolve the underlying discrepancy. The orthodontist should treat deep bite not as a disease entity; instead as a clinical manifestation of an underlying skeletal and/or dental discrepancy. This was clarified in a study conducted by El Dawlatly et al. [3] in which a group of 124 non-growing deep bite patients were analyzed and they concluded that deep bite malocclusion underlies a multitude of skeletal and dental components that should be all considered during the treatment planning process, accordingly a customized treatment mechano-therapy should be tailored for every individual case in order to resolve the underlying discrepancy.

\section{Materials and methods}

As a clinical application of the above mentioned, the aim of this study is to aid the clinical orthodontist in following a thorough stepwise systematic diagnostic approach in the decision making process of deep bite treatment. A systematic diagnostic sheet is proposed as an aid to the orthodontist in designing the treatment objectives. The causative factors (components) were extracted from lateral cephalometric radiographs and study models of 124 non-growing deep bite cases [3]. The age of the included subject was 14 to 22 years and the selection of the subjects was based on following criteria:
a) Deep overbite more than $5 \mathrm{~mm}$.
b) Absence of missing teeth

c) Complete eruption of the $2^{\text {nd }}$ molars

d) No history of orthodontic treatment

e) No restriction regarding the sagittal discrepancy (all Angle's classifications were included)

f) Absence of severe craniofacial disorders.

The following measurements were assessed in order to extract the most important causative factors (Figures 1 and 2) that may contribute to the malocclusion:

a) Dental cephalometric measurements:

i) Maxillary anterior alveolar and basal height $(\mathrm{Mx}-\mathrm{AABH}, \mathrm{mm})$

ii) Maxillary posterior alveolar and basal height $(\mathrm{Mx}-\mathrm{PABH}, \mathrm{mm})$

iii) The inclination of the upper incisors (U1/SN)

iv) Mandibular anterior alveolar and basal height (Md-AABH, mm)

v) Mandibular posterior alveolar and basal height (Md-PABH, $\mathrm{mm}$ )

vi) The inclination of the lower incisors (L1/MP)

b) Skeletal cephalometric mesuements:

i) Mandibular plane angle (MndP-FH)

ii) Gonial angle (Ar-Go-Me)

iii) Maxillary plane angle (SN-MaxP)

c) Dental cast measurements:

i) The length of the clinical crown of the upper central incisors.

ii) The length of the clinical crown of the lower central incisors.

iii) The curve of Spee

Correspondence to: Yehya A Mostafa, Department of Orthodontics and Dentofacial Orthopedics, Faculty of Oral and Dental Medicine, Cairo University, 52 Arab League Street, Mohandesseen, Giza, Egypt, Tel: 002-012-213-1934; Fax: 333471037; E-mail: mangoury@usa.net

Received: May 01, 2015; Accepted: June 23, 2015; Published: June 27, 2015 


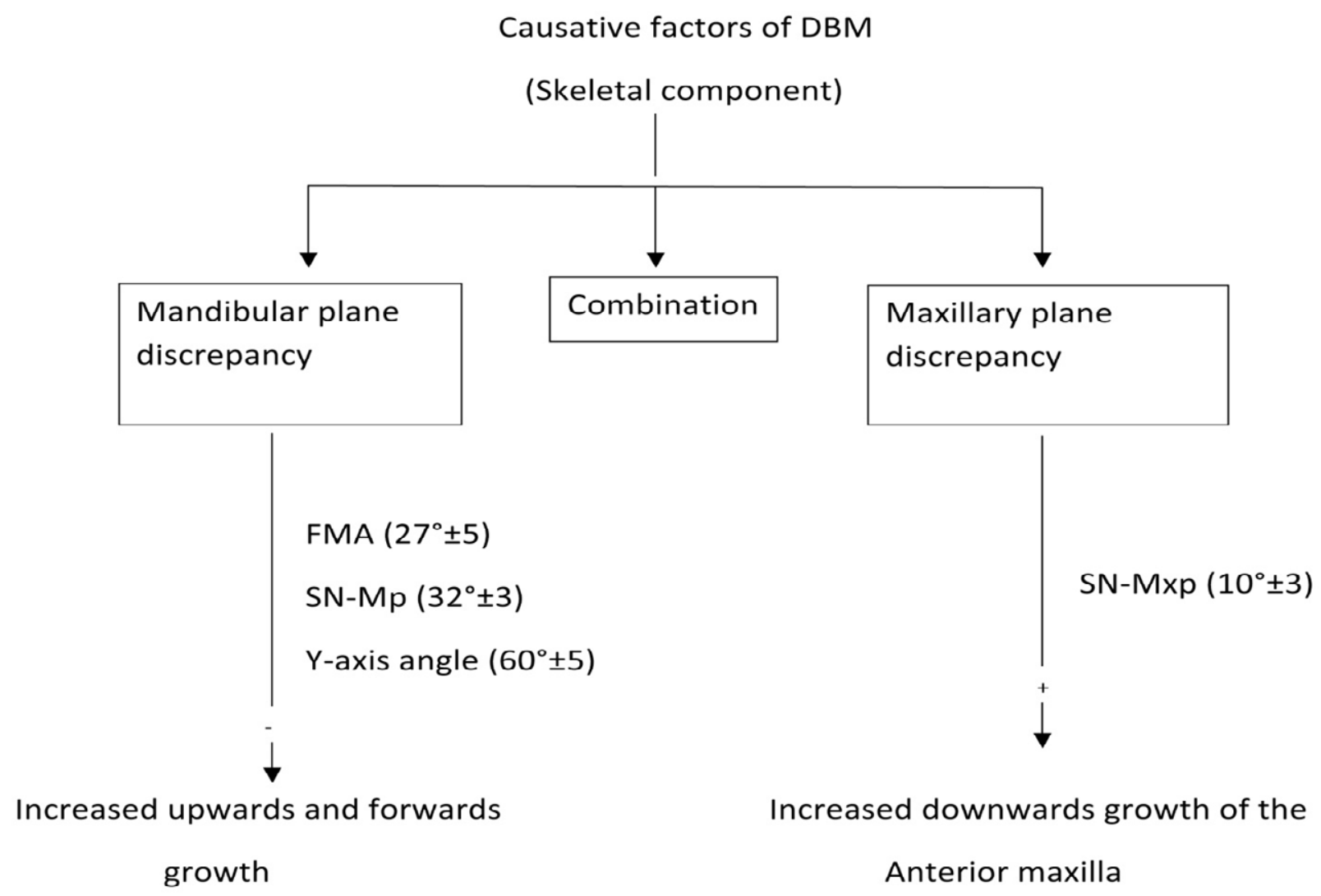

Figure 1. Skeletal causative factors of deep bite malocclusion.

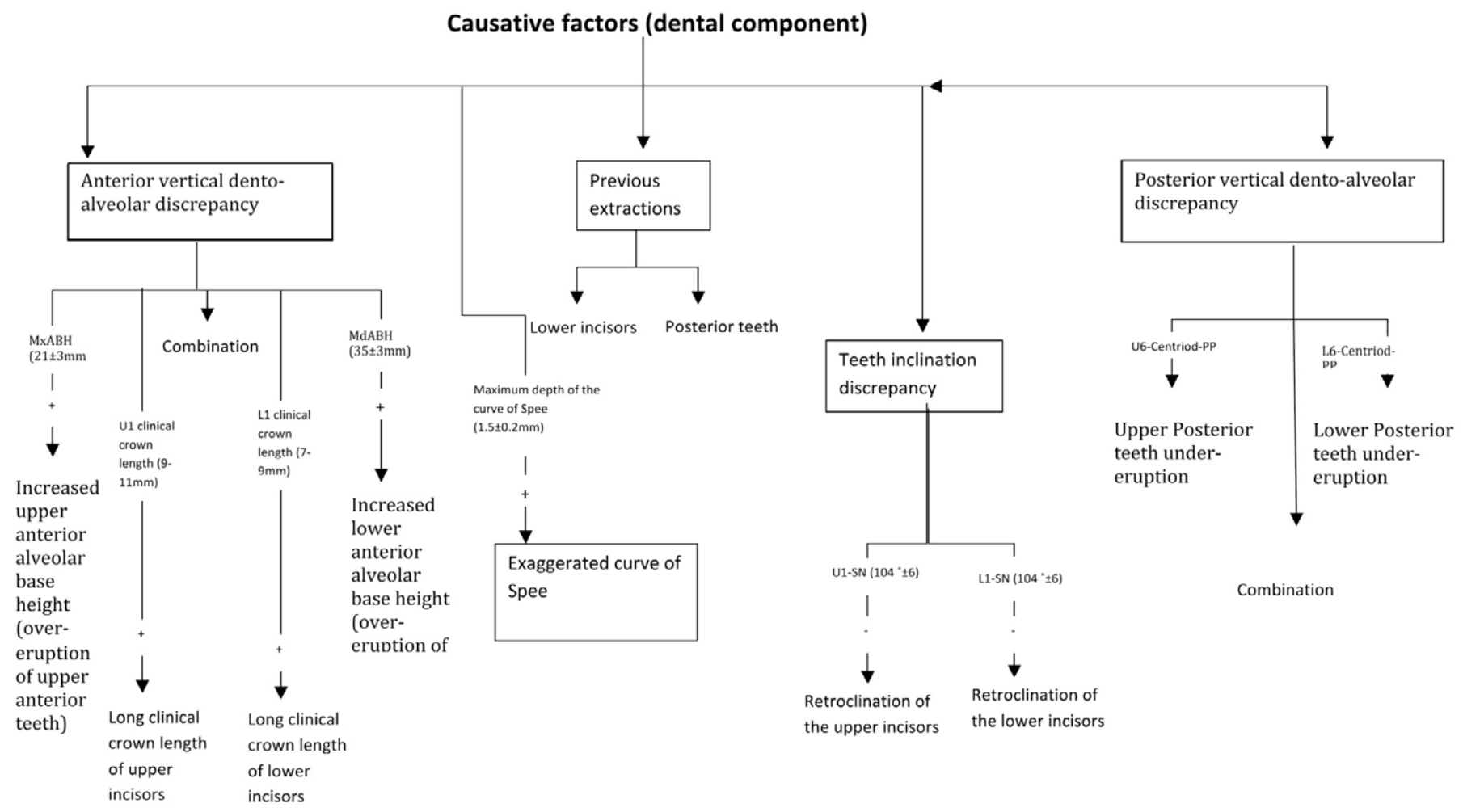

Figure 2. Dental causative factors of deep bite malocclusion. 
Cephalometric and cast measurements of 10 cases were both repeated by the same observer and by a second observer to measure the intra- and inter- observer reliability.
While the contributing factors (Figure 3 and Table 1) and the mechanical parameters (Table 2) were extracted from a thorough literature review. Five electronic databases were searched till January

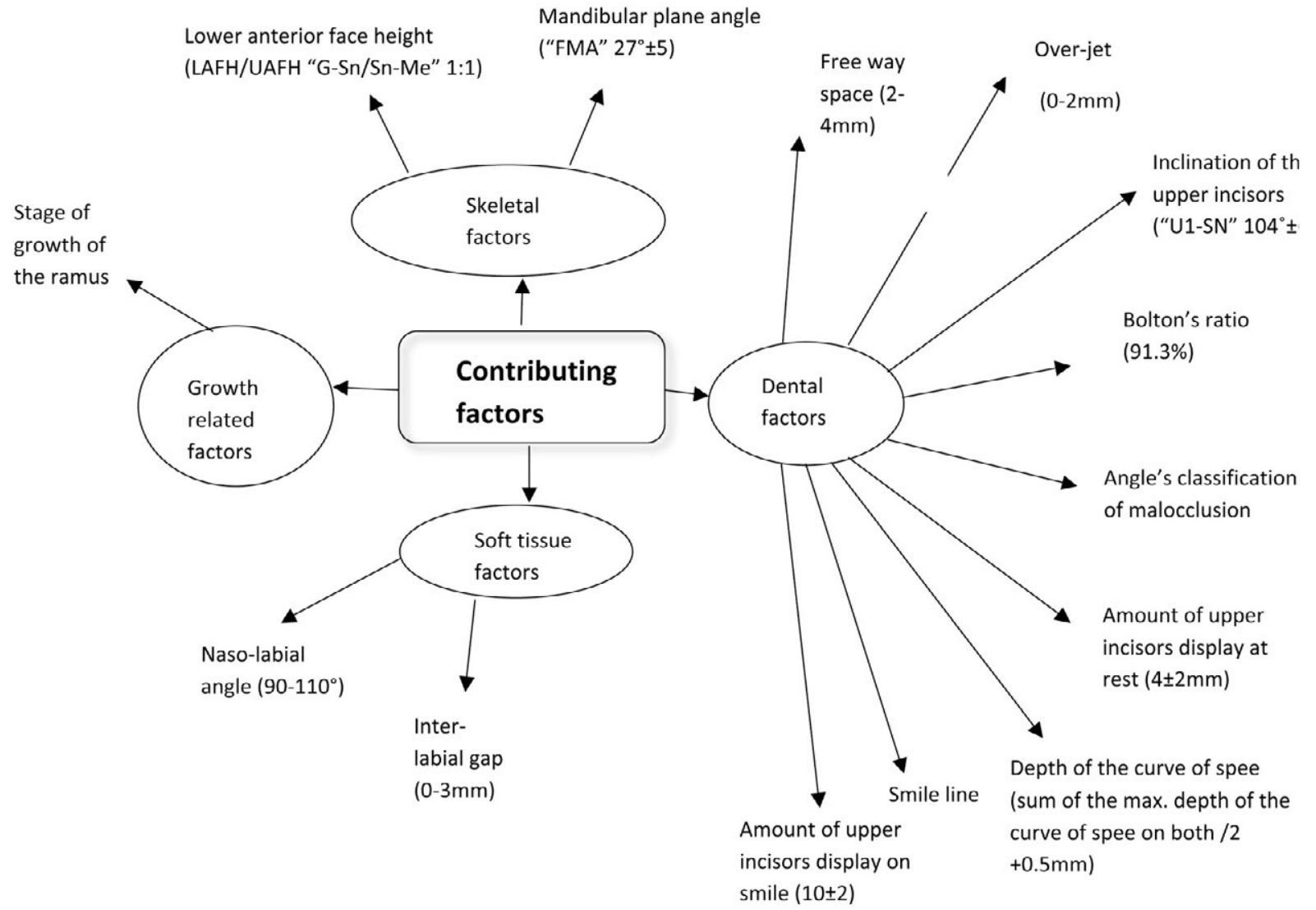

Figure 3. Contributing factors to the decision making process in the treatment planning phase.

Table 1. Effect of the variation of the contributing factors on designing DBM treatment mechanics.

\begin{tabular}{|c|c|c|}
\hline Factor (Norm) & variability & Effect on the mechanics \\
\hline Inter-labial gap (0-3 mm) & increased & Contraindicates extrusion of posterior teeth. \\
\hline Mandibular plane angle ( FMA $27^{\circ} \pm 5$ ) & Steep & Contraindicates extrusion of posterior teeth. \\
\hline Free way space $(2-4 \mathrm{~mm})$ & increased & Provides a room for extrusion of posterior teeth \\
\hline $\begin{array}{l}\text { Lower anterior facial height /upper } \\
\text { anterior facial height }(1: 1)\end{array}$ & increased & Contraindicates extrusion of posterior teeth. \\
\hline $\begin{array}{l}\text { Smile line } \\
\text { (parallel to the curvature of the lower lip) }\end{array}$ & flat & Contraindicates intrusion of anterior teeth \\
\hline $\begin{array}{l}\text { Amount of upper incisors display at rest } \\
(4 \pm 2 \mathrm{~mm})\end{array}$ & increased & Favours intrusion of anterior teeth. \\
\hline $\begin{array}{l}\text { Amount of upper incisors show on smile } \\
(10 \pm 2 \mathrm{~mm})\end{array}$ & increased & Favours intrusion of anterior teeth \\
\hline \multirow[t]{2}{*}{$\begin{array}{l}\text { Inclination of the upper incisors } \\
\text { "U1-SN" }\left(104^{\circ} \pm 5\right)\end{array}$} & proclined & $\begin{array}{l}\text { If intrusive arch used, Intrusive force should be applied posterior to the centre of resistance of the anterior } \\
\text { segment/ } \\
\text { If anterior bite plate used, should not touch the palatal surface of the upper incisors }\end{array}$ \\
\hline & retroclined & $\begin{array}{l}\text { If intrusive arch used, Intrusive force should be applied anterior to the centre of resistance of the anterior } \\
\text { segment } \\
\text { If anterior bite plate used, should touch the palatal surface of the upper incisors. }\end{array}$ \\
\hline Naso-labial angle $(120 \pm 5)$ & decreased & Further proclination of the upper incisors is contraindicated. \\
\hline \multirow[t]{2}{*}{ Bolton's ratio $(91.3 \%)$} & $\begin{array}{l}\text { Low ratio (increased } \\
\text { Maxillary teeth mass) }\end{array}$ & Stripping of upper anterior teeth. \\
\hline & $\begin{array}{l}\text { High ratio (increased mandibular } \\
\text { teeth mass) }\end{array}$ & Stripping of lower anterior teeth. \\
\hline Stage of growth of the ramus & Growing ramus & More stable results after extrusion of posterior teeth \\
\hline \multirow[t]{2}{*}{ Class II Angle's classification } & Division 1 & intrusion of lower incisors is required \\
\hline & Division 2 & Usually proclination of the upper and lower incisors is required \\
\hline
\end{tabular}


Table 2. Effect of parameters change on the amount of overbite.

\begin{tabular}{|c|c|c|}
\hline Parameter & Change in the parameter & Consequent change in overbite \\
\hline U1-SN & $-1{ }^{\circ}$ & $-0.05 \mathrm{~mm}$ \\
\hline L1-MP & $0.8 \mathrm{~mm}$ leveling of the curve of spee & $-0.05 \mathrm{~mm}$ \\
\hline Curve of Spee & $1 \mathrm{~mm}$ extrusion & $-0.05 \mathrm{~mm}$ \\
\hline Extrusion in the posterior buccal segment & $+1 \mathrm{~mm}$ & $-0.5 \mathrm{~mm}$ \\
\hline Over-jet & A maximum of $1.5 \mathrm{~mm}$ (non-growing individuals) & $-1.5 \mathrm{~mm}$ \\
\hline Intrusion of upper anterior teeth & A maximum of $1.9 \mathrm{~mm}$ (non-growing individuals) & $-1.9 \mathrm{~mm}$ \\
\hline Intrusion of lower anterior teeth & \\
\hline
\end{tabular}

2014, these were MEDLINE, EMBASE, OVID, LILACS and THE COCHRANE LIBRARY. Hand searching of orthodontic journals; American Journal of Orthodontics and Dentofacial Orthopedics, Angle Orthodontist, European journal of Orthodontics, Journal of Orthodontics.

The search resulted in 984 citations, and after removal of duplicates and irrelevant articles only 117 articles were used to extract the above mentioned factors and parameters.

\section{Results}

Regarding the dental causative factors, the exaggerated curve of Spee showed the highest contribution in DBM (78\%) followed by the over eruption of the upper incisors (66.1\%). On the other hand considering the skeletal components, the decreased gonial angle was found to be the most skeletal component contributing to DBM (37.1\%) followed by the maxillary plane clock-wise 3 rotation $(32.2 \%)$. While all the other dental and skeletal factors shared with variable percentages in the malocclusion. Where, the least contributing dental causative factor was the increased clinical crown length of the lower incisors (12.1\%). While the least contributing skeletal factor was the mandibular plane angle (19.3\%).The intra-observer and inter-observer reliability analysis was calculated using concordance correlation coefficient (CCC), recording high CCC value; indicating reliable measurements

Accordingly, since all the tested causative factors shared with variable percentages in developing the malocclusion, they were all included in the created decision support sheet (Figure $4 \mathrm{a}$ and $4 \mathrm{~b}$ ).

Regarding the contributing factors and mechanical parameters, the search done resulted in designing the most important:

a) 14 contributing factors (that doesn't cause deep bite but they do affect the decision making process when planning the treatment mechanics) (Figure 3).

b) 7 mechanical parameters (that are some treatment mechanics that are built to resolve other problems during treatment but eventually they have a direct effect on the anterior over-bite) (Table 2).

The created deep bite decision support sheet was designed to include all the above mentioned causative, contributing factors, and mechanical parameters. In every deep bite case all the measurements included in the scheme should be filled in order to design an individualized treatment plan for every individual case without missing any of the above mentioned factors. Two cases are presented as an example of the technique of using this diagnostic protocol for defining the treatment objectives (Figure 5 and 6).

\section{Discussion}

\section{Causative factors}

Skeletal deep bite (Figure 1) could result from a discrepancy in the vertical position of the maxilla, mandible, or their cant [4]. If there is an increased maxillary downward and backward growth and/or an increased mandibular upward and forward growth, this would result in DBM. It has been shown that the vertical component of mandibular growth has a more remarkable effect than the rotational component $[5,6]$, and that the mandibular skeletal changes are twice as important as the mandibular dental changes and about 2.5 times as important as the maxillary changes in inducing overbite change.

Dental deep bite (Figure 2) may be caused by an anterior dentoalveolar vertical discrepancy. The over-eruption of the upper anterior teeth or the lower anterior teeth causes dental deep bite [7]. DBM may be also caused by the under-eruption of the upper or the lower posterior segments [8].

The exaggerated curve of Spee is a main factor in DBM $[9,10]$, where the lower incisors are retroclined and over-erupted.

The extraction of teeth could also deepen the bite because of the loss of the vertical holding wedges after the extraction of posterior teeth [11]. The extraction of lower incisors leads to a collapse of the lower arch with a consequent deepening of the bite [12].

Discrepancy in the inclination of the anterior teeth has an effect on bite depth. Retroclined upper anterior teeth cover a greater length of lower anterior teeth [13], while the retroclined lower anterior teeth lead to a collapse of the lower arch [14].

\section{Contributing factors}

These are factors that do not cause DBM, but affect the decision making process in designing the treatment mechanics. They are categorized into growth-related, skeletal, dental, and soft tissue factors (Table 1 and Figure 3).

The growth factor: In a growing patient with a skeletal deep bite, growth modification is the treatment of choice. The stage of growth can be determined using the cervical vertebrae maturation index (CVM) [15]. It was proven that the growing deep bite subjects attain their peak pubertal growth changes 2 years after the open bite subjects [16]. Therefore, growth modification should be attempted late, in the terminal period of the pubertal growth spurt.

The vertical growth of the ramus increases the free way space between the jaws. Therefore, the growth status of the mandibular ramus is of great importance in case of extruding the posterior teeth. If the ramus is still growing, this provides room for the extrusion procedure, a better neuro-muscular adaptive capability and the long term stability of the extruded teeth is more secured [17].

Skeletal contributing factors: Evaluating lower anterior facial height is important, since in a long face extrusion of posterior teeth should be avoided in order not to aggravate the problem [18].

Dental contributing factors: The display of the upper incisors 
a

DBM Diagnostic procedure:

Aimed overbite:

Correction required:

Step 1 (Growth status)

- Age:

Sex:

- CVMI stage:

Step 2 (skeletal status):

Mandiblular measurements:

- $F M A(27+1-5):$

increased

normal

decreased

$Y$-axis angle $(60+1-5)$ :

Increased

Normal

decreased

SN-Mp (32+/-3):

Increased

Normal

Decreased

Maxillary plane measurements:

- MMA angle (27+/-5):

Increased

Normal

SN-Mxp angle $(10+/-3):$

SN-Mxp a

Increase

Derre

Decreased

Step 3 (Dento-alveolar status)

Anterior teeth vertical discrepancy

- "MXABH" $(21+/-3 \mathrm{~mm})$

Increased

Normal

decreased

"U1 crown length" $(10.5 \pm 1 \mathrm{~mm})$

Increased

Normal

Decreased

"MnABH**" (35 +/-3 mm):

- Increased

- Normal

"Liclinical crown length" (9ะ1mm)

- Increased

Normal

Decreased

"U6 PP mm" (26+3).

"U6_PP mm"
Over-eruption
Normal

Under-eruption

"L6_MP mm" (35*3)

Over-eruption
Normal

Normal
Under-eruption

"U1-SN" (104+/.6):

- $1.5 \mathrm{sN}(104+1$

Increased

Normal

decreased

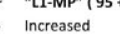

Increased

Normal
Decreased

Extracted and/or missing posterior tooth no.

Extracted and or missing lower incisor no.

Step 4 (Contributing factors)

1) Clinical examination:

smile line
Flat

normal
Exaggerated

Inter-labial gap "Ustm- Lstm" (0-3m

Normal

increased
Upper incisors display at rest "Ustm-U1 incisal edge"

(3.2mint

(3ะ2mm)

Normal

Increased

way space "Sn-Me at rest position- Sn-Me at

maximum intercuspation" (2-4 mm)

Increased

Within norma

Deficient

Upper incisors and gingival display on smile

$(10 \pm 2):$

increased

normal

deficient

2) Cast analysis

ysis

The amount of over-et $(0-2 \mathrm{~mm})$

Bolton ratio between upper and lower teeth $(91.3$

Angle's classification of malocclusion:

Class I Class II div1 class II div2 Class III

3) Cephalometric analysis

Lower anterior facial height "G-Sn: Sn-Me mm (1:1)

Increased

Normal

decreased

Mandibular plane "FMA" $(27+/-5)$ :

increased

Normal

Decreased

4) Stage of growth of the ramus:

b

Outcome 1 (growth status):

Outcome 2 (skeletal status)

Outcome 3 (dento-alveolar status)

Outcome 4 (contributing factors):

Final outcome:

Treatment

objectives:

* MxABH: The upper anterior alveolar height (distance in $\mathrm{mm}$ between the midpoint of the alveolar meatus and the point of intersection between the palatal plane and the maxillary alveolar axis).

** MnABH: The lower anterior alveolar height "(The mm distance between the midpoint of alveolar meatus of mandibular central incisor and the intersection between symphysial surface and mandibular alveolar axis).

Figures $4 \mathbf{a}$ and $\mathbf{4 b}$. The proposed new diagnostic paradigm. 


\section{Case 1}
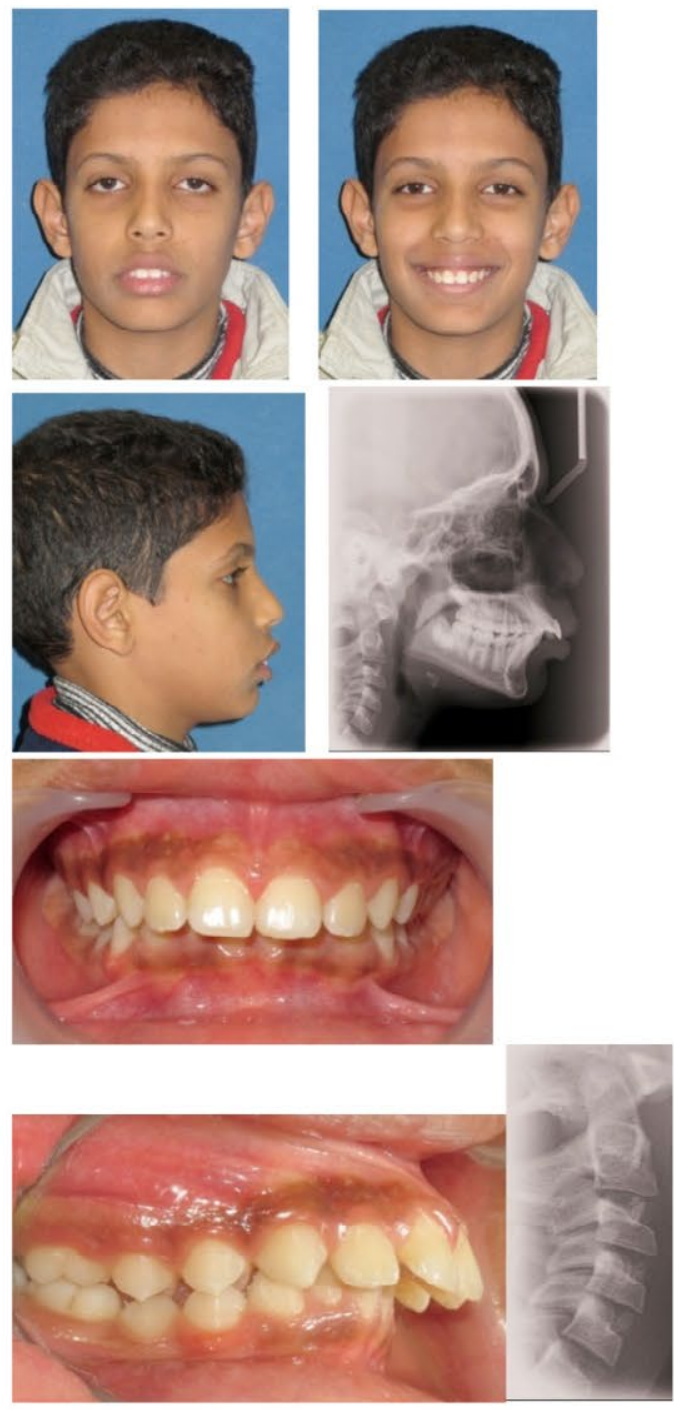

Age: 12.

Bite depth: $6.5 \mathrm{~mm}$.

Aimed end result of overbite: $1 \mathrm{~mm}$.

Correction required: $5.5 \mathrm{~mm}$.

\section{1) Growth status:}

- Stage 2 CVMI (cervical vertebrae maturation index).
- Peak mandibular growth spurt is approximately 1 year away.

- Patient is still growing.

2) Skeletal status:

- Slight increase in the downward and backward rotation of the anterior part of the maxilla.

- (A skeletal maxillary component is contributing to DBM).

3) Dento-alveolar status:

- Over-eruption of upper and lower anterior teeth.

- A slight long clinical crown length of the lower central incisors.

- Proclined upper incisors.

4) Contributing factors:

- Normal smile line.

- Increased upper incisors display at rest.

- Increased upper incisors and gingival display on smile.

- Very deep curve of Spee.

- Class II div 1 malocclusion.

- Increased lower anterior facial height.

- Increased overjet.

\section{Treatment objectives:}

Control posterior dentoalveolar segments and intrude upper and lower incisors

\section{Case 2}

Figure 5. Clinical application of the new paradigm. 


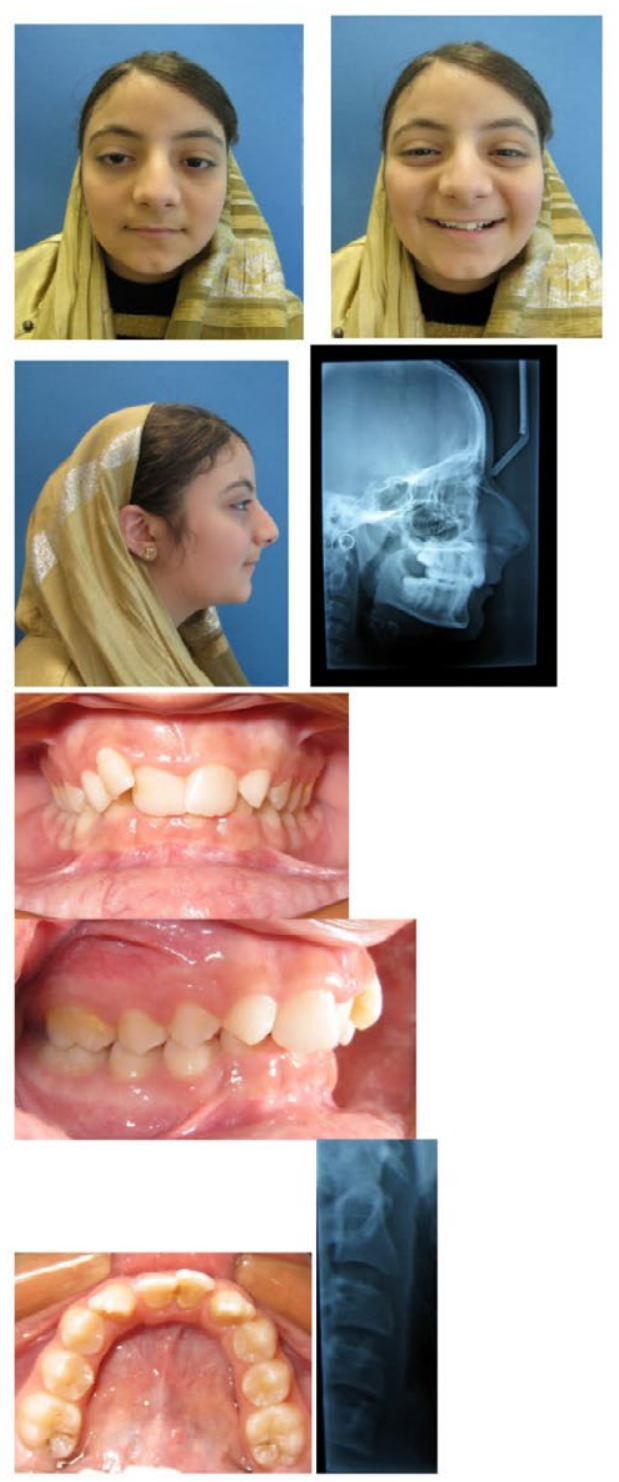

Age: 12 .

Bite depth: $9 \mathrm{~mm}$.

Aimed end result of overbite: $2 \mathrm{~mm}$.

Correction required: $7 \mathrm{~mm}$.
- Peak mandibular growth spurt occurs in this stage.

- Patient is still growing.

2)

\section{Skeletal status:}

- Increased upward and forward rotation of the mandibular base.

(skeletal mandibular component sharing in DBM).

3)

\section{Dento-alveolar status:}

- Under-eruption of upper and lower posterior teeth.

- Retroclined upper incisor.

- Missing 2 lower lateral incisors.

\section{4) Contributing factors:}

- Flat smile line

- Decreased upper incisors display at rest

- Decreased upper incisors display on smile

- Deep curve of Spee

- Class II div 2 malocclusion

- Decreased lower anterior facial height

\section{Treatment objectives:}

Encourage eruption of upper and lower posterior segments and avoid intrusion of upper incisors

1) Growth status:

- Stage 3 CVMI (cervical vertebrae maturation index).

Figure 6. Clinical application of the new paradigm. 
at rest and the amount of upper incisor show on smile influence the treatment decision. Excessive incisor display favors intrusion of upper anterior teeth. Conversely, normal or decreased incisor display favor extrusion of posterior teeth and/or intrusion of lower anterior teeth .The smile arc curvature has a bearing on the treatment of choice for deep bite patients. In case of a flat or nearly flat smile arc, intrusion of upper incisors is contraindicated [19-23].

The ratio between the mesio-distal width of the upper and lower teeth will affect bite depth. According to Bolton a normal acceptable overbite could be attained only if a balanced ratio (91.3\%) between the upper and lower teeth is reached [20,21].

Regarding Angle's classification of malocclusion, a deep overbite that is caused by the over-eruption of lower anterior teeth due to the increased overjet is associated with the growth factor malocclusion. While in skeletal contributing factors; deep overbite is the direct result of retroclined upper incisors that cover most of the lower incisors height [22-23].

In case of using intrusive arches, the degree of upper incisors inclination affects the point of application of the intrusive force during incisors intrusion [24]. Also their inclination affects the design of the bite raising device or the anterior bite plate, depending on whether there is a need to flare the upper incisors or not.

The available free way space should be precisely measured. A sufficient free way space would permit the extrusion of posterior teeth and decrease the tendency for relapse [25].

Soft tissue contributing factors: An increased inter-labial gap would be aggravated by extruding the posterior teeth. The naso-labial angle limits the proclination of the upper incisors as a treatment option for DBM. In case of a reduced naso-labial angle, proclination of the upper incisors is contraindicated [26].

\section{The Mechanical parameters}

These are some parameters that are built to resolve certain problems during treatment, and at the same time they have a direct effect on the depth of the bite (Table 2).

Changing the inclination of the upper incisors has been found to have a direct effect on the amount of overbite; there is a negative correlation between the inclination of the upper incisors and the amount of overbite where a decrease of 6 degrees in their inclination results in a $0.3 \mathrm{~mm}$ increase in overbite. Any change in the amount of overjet during the various treatment procedures affects the amount of overbite; with every $1 \mathrm{~mm}$ increase in overjet the overbite is reduced by $0.05 \mathrm{~mm}[27]$.

Considering the extrusion of posterior teeth, it has been proven that every $1 \mathrm{~mm}$ of posterior extrusion opens the bite anteriorly by $1.5 \mathrm{~mm}$ [28]. This finding emphasizes that small amounts of molar extrusion can result in significant anterior bite opening.

The intrusion of the upper incisors is proposed in many studies as the ideal treatment option for DBM [29].

According to a recent systematic review it was found that, for nongrowing individuals, a maximum of $1.5 \mathrm{~mm}$ upper incisors intrusion and $1.9 \mathrm{~mm}$ lower incisors intrusion could be attained [30].

In addition to the effect of leveling the Curve of Spee on the vertical position of the incisors, the use of straight wires for leveling causes proclination of the incisors. The degree of proclincation can be calculated from the equation [(the sum of the maximum curve of Spee on both sides/2) $+0.5 \mathrm{~mm}$ ]; for every $0.8 \mathrm{~mm}$ required for leveling the curve of Spee there is $1^{\circ}$ proclination in the lower incisors with further opening of the bite [31].

Not only the antero-posterior changes affect the bite depth, but also the transverse changes have a remarkable influence [32,33]. Rapid maxillary expansion, attained in growing subjects, was found to cause an increase in the downward and backward rotation of the mandible, increase in the lower facial height and a decrease in the overbite [34].

\section{The proposed decision support scheme}

In order to follow the current protocol aiming to customize the treatment plan for deep bite cases, the clinician should:

a) Extract all the measurements listed in the sheet from the patient's lateral cephalogram and study model.

b) Classify the problem list into 4 sections; the growth status, dental, skeletal status and the contributing factors. This is applied in Figure 5 and 6.

c) Specify the treatment objectives and the bite opening mechanics according to what is dictated by the extracted data.

\section{Conclusions}

The orthodontist's approach in treating DBM should resemble the physician's approach in managing fever. The physician regards fever as a symptom of an underlying pathological condition. Likewise, the orthodontist should be aware that DBM is not a disease entity, but rather a clinical manifestation of an underlying skeletal and/or dental discrepancy. By following the proposed diagnostic procedure (Figure $4 \mathrm{a}$ and $4 \mathrm{~b}$ ), which takes into account all factors that affect DBM, an efficient, factor-based treatment plan is established. Two cases are presented to emphasize the clinical utility of this approach (Figures 5 and 6).

By systematically following the suggested deep bite diagnosis procedures [35,36] the two cases presented were found to be divergent regarding causative and contributing factors. The systematic consideration of all factors could provide individualized treatment objectives for deep bite correction.

\section{References}

1. Keim RG (2008) Fine-tuning our treatment of deep bites. J Clin Orthod 42: 687-688. [Crossref]

2. Proffit WR and Fields HW (2007) Contemporary Orthodontics. C.V. Mosby Co, St Louis: 3-92.

3. El-Dawlatly MM, Fayed MM, Mostafa YA (2012) Deep overbite malocclusion analysis of the underlying components. Am J Orthod Dentofacial Orthop 142: 473 480. [Crossref]

4. Nanda SK (1990) Growth patterns in subjects with long and short faces. Am J Orthod Dentofacial Orthop 98: 247-258. [Crossref]

5. Naumann SA, Behrents RG, Buschang PH (2000) Vertical components of overbite change: a mathematical model. Am J Orthod Dentofacial Orthop 117: 486-495. [Crossref]

6. Björk A (1969) Prediction of mandibular growth rotation. Am J Orthod 55: 585-599. [Crossref]

7. Ceylan I, Eröz UB (2001) The effects of overbite on the maxillary and mandibular morphology. Angle Orthod 71: 110-115. [Crossref]

8. Pearson LE (1973) Vertical control through use of mandibular posterior intrusive forces. Angle Orthod 43: 194-200. [Crossref]

9. Bayda $\AA$ Ÿ B, Yavuz I, Atasaral N, Ceylan I, DaÄŸsuyu IM (2004) Investigation of the 
changes in the positions of upper and lower incisors, overjet, overbite, and irregularity index in subjects with different depths of curve of Spee. Angle Orthod 74: 349-355. [Crossref]

10. Marshall SD, Caspersen M, Hardinger RR, Franciscus RG, Aquilino SA, et al. (2008) Development of the curve of Spee. Am J Orthod Dentofacial Orthop 134: 344-352. [Crossref]

11. Garlington M, Logan LR (1990) Vertical changes in high mandibular plane cases following enucleation of second premolars. Angle Orthod 60: 263-267. [Crossref]

12. Faerovig E, Zachrisson BU (1999) Effects of mandibular incisor extraction on anterior Occlusion in adults with Class III malocclusion and reduced overbite. Am J Orthod Dentofacial Orthop 115: 113-24. [Crossref]

13. Lin JX1 (1990) The importance of variability in morphologic feature of upper centra incisors in linguoversion anterior deep over bite. Zhonghua Kou Qiang Yi Xue Za Zhi 25: 273-276, 317-8. [Crossref]

14. Sangcharearn Y, Ho C (2007) Effect of Incisor Angulation on Overjet and Overbite in Class II Camouflage Treatment. A typodont study. Angle Orthod 77: 1011-1018. [Crossref]

15. Baccetti T, Franchi L, McNamara JA Jr (2002) An improved version of the cervica vertebral maturation (CVM) method for the assessment of mandibular growth. Angle Orthod 72: 316-323. [Crossref]

16. Nanda SK1 (1988) Patterns of vertical growth in the face. Am J Orthod Dentofacial Orthop 93: 103-116.

17. Cevidanes LH, Franco AA, Gerig G, Proffit WR, Slice DE, et al. (2005) Assessment of mandibular growth and response to orthopedic treatment with 3-dimensional magnetic resonance images. Am J Orthod Dentofacial Orthop 128: 16-26. [Crossref]

18. Nanda R, Kuhlberg A (2005) Management of Deep Overbite Malocclusion, Biomechanics and esthetic strategies in clinical orthodontics, Ed: Nanda.R, , Elsevier Saunders Company:131-155.

19. Zachrisson BU (1998) Esthetic Factors Involved in Anterior Tooth Display and the Smile Vertical Dimension. J Clin Orthod 32: 432-445.

20. Bolton WA (1958) Disharmony in tooth size and its relation to the analysis and the treatment of malocclusion. Angle Orthod 28: 113-130.

21. Bolton WA (1962) The clinical application of a tooth size analysis. Am J Orthod 48 : 504-529.

22. Rothstein T, Yoon-Tarlie C (2000) Dental and facial skeletal characteristics and growth of males and females with class II, division 1 malocclusion between the ages of 10 and 14 (revisited)-part I: characteristics of size, form, and position. Am J Orthod Dentofacial Orthop 117: 320-332. [Crossref]

23. Stahl F, Baccetti T, Franchi L, McNamara JA Jr (2008) Longitudinal growth change in untreated subjects with Class II Division 1 malocclusion. Am J Orthod Dentofacial Orthop 134: 125-137. [Crossref]

24. Vanden Bulcke MM, Dermaut LR, Sachdeva RC, Burstone CJ (1986) The center of resistance of anterior teeth during intrusion using the laser reflection technique and holographic interferometry. Am J Orthod Dentofacial Orthop 90: 211-220. [Crossref]

25. Moyers RE, Riolo ML (1988) Early treatment. Handbook of orthodontics fourth edition. Year Book Medical Publishers, Inc. Chicago, London, Bocarton: 423-426.

26. Lo FD, Hunter WS (1982) Changes in nasolabial angle related to maxillary incisor retraction. Am J Orthod 82: 384-391. [Crossref]

27. Ceylan I, Baydas B, Bölükbasi B (2002) Longitudinal cephalometric changes in incisor position, overjet, and overbite between 10 and 14 years of age. Angle Orthod 72: 246250. [Crossref]

28. Noroozi H1 (1999) A simple method of determining the bite-opening effect of posterior extrusion. J Clin Orthod 33: 712-714. [Crossref]

29. Burstone CR (1977) Deep overbite correction by intrusion. Am J Orthod 72: 1-22 [Crossref]

30. Ng J, Major PW, Heo G, Flores-Mir C (2005) True incisor intrusion attained during orthodontic treatment: a systematic review and meta-analysis. Am J Orthod Dentofacia Orthop 128: 212-219. [Crossref]

31. Bishara S (2001) Tooth size arch length analysis. Textbook of orthodontics. Saunders Company W.B.:143

32. Wertz RA (1970) Skeletal and dental changes accompanying rapid midpalatal suture opening. Am J Orthod 58: 41-66. [Crossref]

33. Majourau A, Nanda R (1994) Biomechanical basis of vertical dimension control during rapid palatal expansion therapy. Am J Orthod Dentofacial Orthop 106: 322-328. [Crossref]

34. Basciftci FA, Karaman AI (2002) Effects of a modified acrylic bonded rapid maxillary expansion appliance and vertical chin cap on dentofacial structures. Angle Orthod 72 61-71. [Crossref]

35. Jacbson A (2006) Radiographic cephalometry from basic to 3D imaging, second edition. Ed: Alexander Jacbson. Quintessence Publishing Co.

36. Nanda R, Goldin B (1980) Biomechanical approaches to the study of alterations of facial morphology. Am J Orthod 78: 213-226. [Crossref]

Copyright: (C2015 El-Dawlatly MM. This is an open-access article distributed under the terms of the Creative Commons Attribution License, which permits unrestricted use, distribution, and reproduction in any medium, provided the original author and source are credited. 